\title{
Laser surface hardening of H13 steel in the melt case
}

\author{
Kwo-An Chiang*, Yong-Chwang Chen \\ Laboratory of Surface Modification, Department of Mechanical Engineering, National Taiwan University, No.1, Sec. 4, Roosevelt Road, Taipei 106, Taiwan
}

Received 27 September 2004; received in revised form 3 February 2005; accepted 4 February 2005

Available online 3 March 2005

\begin{abstract}
Laser heating caused a melting layer to form on the H13 steel, which usually has bad thermal conductivity and diffusivity. Therefore, the modified Ashby-Eastering heat-transfer equation was used to provide the temperature field for laser surface hardening in the melt. When the laser hardened H13 steel through surface melting, the basic microstructure of the dendrites was surrounded by an extremely fine lamellar structure in the melt layer. It is clear that the contours of the melting point isotherms and the critical phase transition temperature of H13 in the quenched and as-received conditions were comparable in the temperature distribution field under different laser energy densities. When the laser moves on, the phase transition temperature of $\mathrm{H} 13$ is raised and it becomes higher than the $A_{1}$ temperature because the heating rate during laser processing is usually $>10^{4}{ }^{\circ} \mathrm{C} / \mathrm{s}$. The larger the grain size or the more heterogeneous the structure, the higher the temperature and the longer the duration required for transforming the steel into austenite.
\end{abstract}

(C) 2005 Elsevier B.V. All rights reserved.

Keywords: Laser transformation hardening; Dendrites; Temperature distribution field; Austenite

\section{Introduction}

High-energy density beam processing is a special technology that uses a high-energy density beam as a heat source for such applications as welding, incision, punching, spray painting, surface treatment, etching, and fine machining [1]. Surface treatments that are effected by laser beam irradiation include laser hardening, laser alloying, and laser cladding $[2,3]$. The common feature of all of these processes is the production of certain thermal cycles in small, highly localized regions on the surface of the work-piece, which then takes on new properties that allow it to cope better with wear, fatigue, and corrosion while maintaining most of its other original properties $[4,5]$.

Recent reviews of the principles and applications of laser treatments describe the use of lasers as a controlled heat source for transformation hardening [6]. The classical approach to modeling the heat flow induced by a distributed heat source moving over the surface of a semi-infinite solid starts with the solution for a point source and intergrates it

\footnotetext{
* Corresponding author. Tel.: +886 2 23684463; fax: +886 223625489

E-mail address: d89522007@ntu.edu.tw (K.-A. Chiang).
}

over the area of the beam. This widely used method requires numerical procedures for its evaluation, as do the finitedifference solutions of Kou and co-workers [7]. They developed a 3-D heat flow model and varied the beam power and traverse speed and determined the dimensional analysis of heat flow during heat treating and melting. But the results were not easy discretion of complex shapes and needed complicated calculation. Another approach of heat flow modeling applied to moving heat sources by Rosenthal and several authors have used finite-element method for numerical evaluation, as do the FEM analyses of Pavelic and co-workers [8]. The FEM analysis was varied the thermal properties and easy discretion and it could consider any flux. But the results needed complicated calculation. The other alternative approach is that of Bass, who presents temperature field equations for various beam geometries by taking limits to extract analytical results. Ashby and Easterling carry the analytical approach further, developing an approximate solution for the entire temperature field [9]. This approach is apparent to be easy calculation and always calibrated by experimental data through the comparison with finite-difference solution and finite-element method. In this paper, we present a modified Ashby-Eastering heat- 
Table 1

Definitions and units

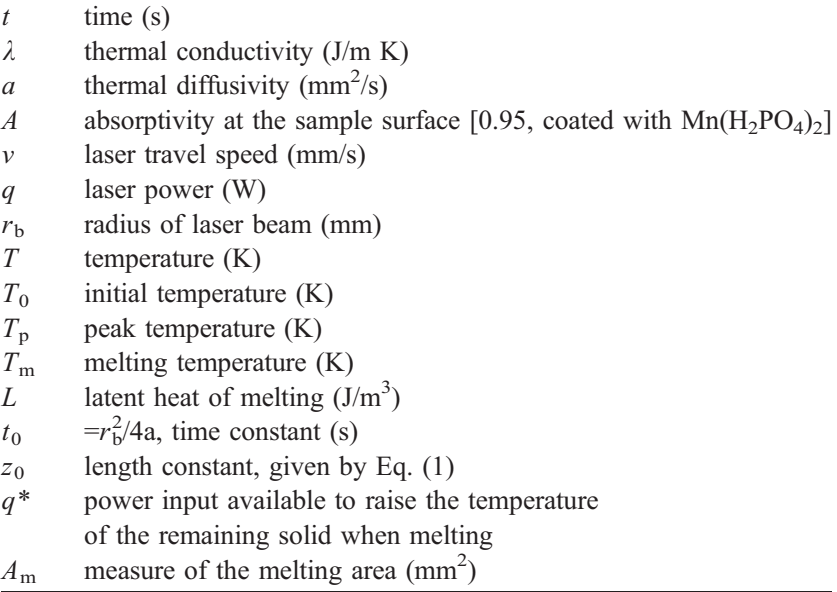

transfer model of the laser hardening process in the melt. When inputting the laser processing parameters and the thermo-physical values, this model can be used to predict the surface temperature at which austenization and subsequent martensite formation takes place. In this present study, we have investigated the effect of laser surface hardening on H13 steel. We studied the phase transformations that occurred by using optical and scanning electron microscopic analyses, and correlated the microstructural behavior by calculating the theoretical temperature profile.

\section{Mathematical modeling}

The laser heating of H13 steel, which has bad thermal conductivity and diffusivity, usually causes a melting layer to form. Therefore, we must change some of the reference parameters in the Ashby-Eastering heat-transfer equation to obtain an expression for the temperature field in the case of laser surface hardening in the melt $[10,11]$ :

$$
\begin{aligned}
T_{\mathrm{p}}-T_{0}= & \frac{A q^{*}}{2 \pi \lambda v\left[t\left(t+t_{0}\right)\right]^{1 / 2}} \\
& \times \exp \left\{\frac{-1}{4 a}\left[\frac{\left(z+z_{0}\right)^{2}}{t}+\frac{y^{2}}{\left(t+t_{0}\right)}\right]\right\}
\end{aligned}
$$

The symbols used in this paper are defined in Table 1. We obtained the position of the melt boundary and of the

Table 2

Thermo-physical parameters of H13 chromium hot work steel

\begin{tabular}{ll}
\hline Properties & Value \\
\hline Thermal conductivity, $\lambda$ & $28.6 \mathrm{~J} / \mathrm{m} \mathrm{K}$ \\
Thermal diffusivity, $a$ & $5.35 \mathrm{~mm}^{2} / \mathrm{s}$ \\
Density, $\rho$ & $7.76 \mathrm{~g} / \mathrm{cm}^{3}$ \\
Latent heat for melting, $L$ & $2 \times 10^{9} \mathrm{~J} / \mathrm{m}^{3}$ \\
Heat capacity, $c$ & $688.4 \mathrm{~J} / \mathrm{kg} \mathrm{K}$ \\
Austeninized temperature, $A_{1}$ & $1010{ }^{\circ} \mathrm{C}$ \\
Melting point, $T_{\mathrm{m}}$ & $1483{ }^{\circ} \mathrm{C}$ \\
\hline
\end{tabular}

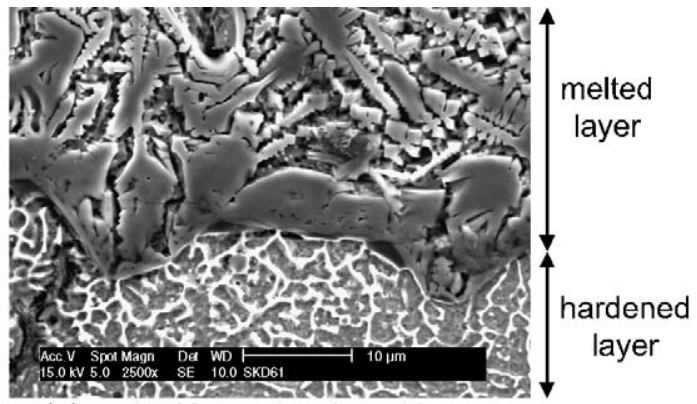

(a) melted layer+hardened layer

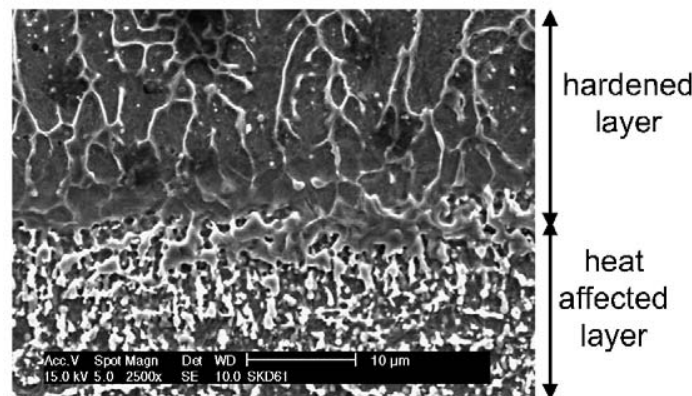

(b) hardened layer+ heat affected layer

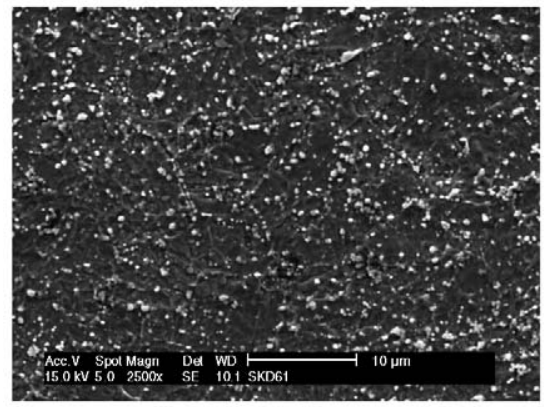

(c) base material

Fig. 1. Cross-sections of the laser-hardened H13 steel upon surface melting.

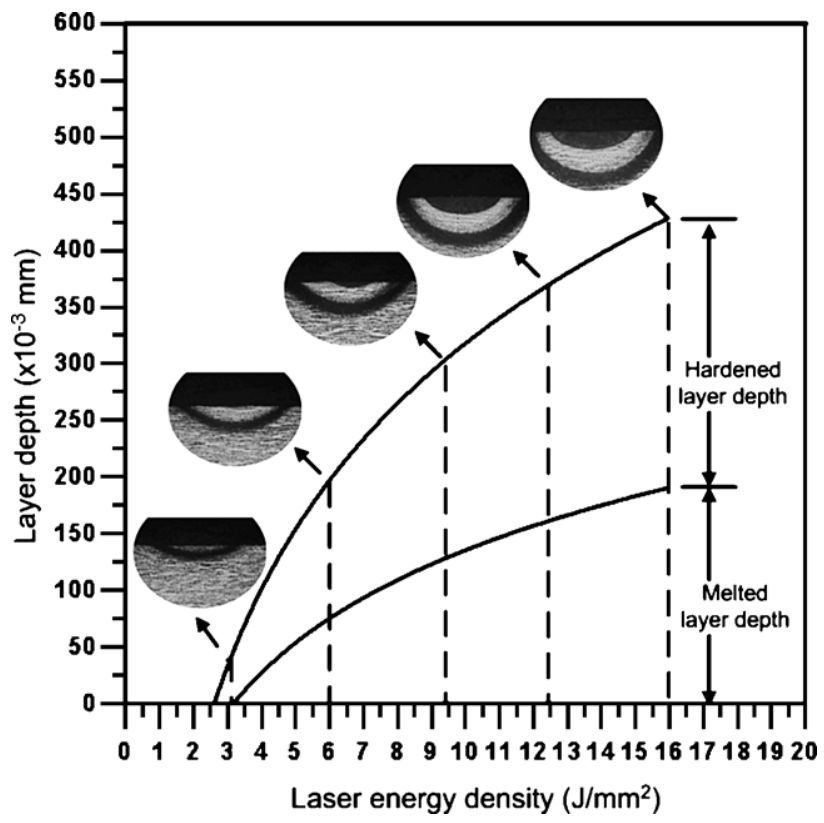

Fig. 2. The depth of the melted and hardened layers of the laser-treated H13 steel under in its quenched condition different laser energy densities. 
contours at which the peak temperature reaches the critical phase transition temperature of $\mathrm{H} 13$ by calculating them from the modified Ashby-Eastering heat-transfer equation (Eq. (1)). The value of $z_{\mathrm{m}}$ is the depth at which the peak temperature $T_{\mathrm{p}}$ just reaches $T_{\mathrm{m}}$; the critical phase transition temperature was $T_{\mathrm{cr}}$. The details, including a small correction for the heat of fusion, are given below. When the surface is melted, energy is absorbed as the latent heat of the liquid forms. Although this energy is released later, it is temporarily removed from the input energy and is not available to melt more material. The volume that melts per second is $v \times A_{\mathrm{m}} \times L$ and the energy available to raise the temperature of the remaining solid is:

$q^{*}=q-v \times A_{\mathrm{m}} \times L$

In Eq. (1), $z_{\mathrm{m}}$, which represents the predicted melting depth, is first approximated as the maximum distance below the center of the laser beam that experiences a peak temperature exceeding the melting temperature of $1423{ }^{\circ} \mathrm{C}$. The peak temperature at depth $z_{\mathrm{m}}$ in the solid is then given by the procedure given earlier, with $q$ replaced by $q^{*}$. This substitution gives an equation that can solve for $z_{\mathrm{m}}$.

\section{Experimental procedure}

Table 2 provide the material properties of H13 steel. The specimen of $\mathrm{H} 13$ steel was machined into a rectangular block $(10 \mathrm{~mm} \times 30 \mathrm{~mm} \times 10 \mathrm{~mm})$ that we used for the laser treatment. The laser treatment was performed using a 2.0$\mathrm{kW}$ continuous wave $\mathrm{CO}_{2}$ laser. To focus the beam, we used a $\mathrm{Zn-Se}$ lens having a 7.5-in. focal length. The laser power and travel speed used in the experiments were in the ranges $150-250 \mathrm{~W}$ and $10-25 \mathrm{~mm} / \mathrm{s}$, respectively, at a beam diameter of $2 \mathrm{~mm}$. To produce oxide-free coatings in all experiments, the laser was shielded using $0.1 \mathrm{mPa} \mathrm{N}_{2}$ gas. Prior to laser treatment, the surface of the specimen was coated with $\mathrm{Mn}\left(\mathrm{H}_{2} \mathrm{PO}_{4}\right)_{2}$ to increase the energy absorption.
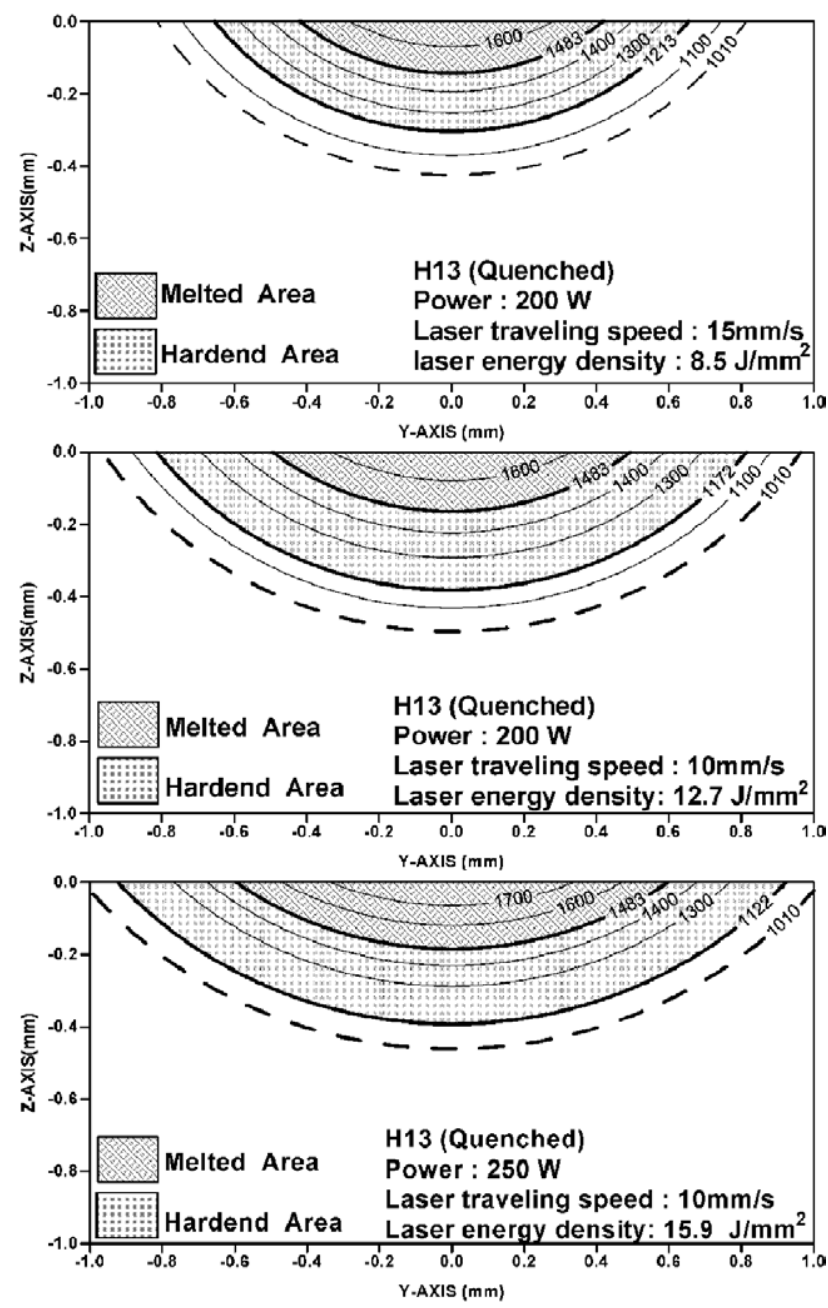

Fig. 3. Temperature distribution field obtained by using the modified Ashby and Eastering heat-transfer equation (Eq. (1)) for the laser surface hardening of H13 steel under different laser energy densities. 


\section{Results and discussion}

Fig. 1 $(\mathrm{a}-\mathrm{c})$ display cross-sections of the laser-hardened base H13 steel upon surface melting. In Fig. 1(a), we note that when the laser moves away, the melted layer begins to solidify. The cooling rate in the liquid state is very high as a result of self-cooling, and $\mathrm{Cr}$ becomes enriched in the remaining liquid regions and a dendritic structure forms.

We note that the basic microstructure of the dendrites was surrounded by an extremely fine lamellar structure that was constituted of metallic carbides, martensite, and, probably, retained austenite caused by the mono-variant eutectic reaction $\mathrm{L} \rightarrow \gamma+\mathrm{M}_{7} \mathrm{C}_{3}$. In the melt layer, $\mathrm{Cr}$ provides oxidation and corrosion resistance, as well as strength through the formation of $\mathrm{Cr}_{7} \mathrm{C}_{3}$ and $\mathrm{Cr}_{23} \mathrm{C}_{6}$ carbides. Fig. 1(b) is characterized by the martensite within the metallic carbides that precipitated in the grain boundary. In the heataffected layer, as indicated in Fig. 1(b), the maximum temperature remained below the austenizing temperature and the particles of $\mathrm{M}_{23} \mathrm{C}_{6}$ and $\mathrm{M}_{7} \mathrm{C}_{3}$ carbides $(\mathrm{M}=\mathrm{Cr}, \mathrm{Fe})$ became larger-and many more formed-as a result of tempering. The base steel presents a spheroidal structure that consists of particles of $\mathrm{M}_{23} \mathrm{C}_{6}$ and $\mathrm{M}_{7} \mathrm{C}_{3}$ carbides $(\mathrm{M}=\mathrm{Cr}, \mathrm{Fe})$ dispersed in a matrix, as indicated in Fig. 1(c).

Fig. 2 indicates that the depth of the melted and hardened layers of the laser-treated, quenched H13 steel increased substantially upon increasing the laser energy densities. Fig. 3 presents a temperature distribution field obtained using the modified Ashby-Eastering heat-transfer equation (Eq. (1)) for laser hardening of $\mathrm{H} 13$ steel in the quenched condition under different laser energy densities. Melting occurs within the slant region; outside the melted layer, the diagram displays temperature contours along which the peak temperature just reaches the critical phase transition temperature of H13 steel as the area becomes hardened. In addition, this figure displays contours of the martensite volume fraction, which increase as the melt boundary is approached. Fig. $3(\mathrm{a}-\mathrm{c})$ demonstrate that the critical phase transition temperature will decrease from 1213 to 1172 to $1122{ }^{\circ} \mathrm{C}$ under laser energy densities of $8.5,12.7$, and $15.9 \mathrm{~J} / \mathrm{mm}^{2}$, respectively. This finding implies that when the laser energy densities increase, the temperatures will be higher and the duration will be longer for the transformation of $\mathrm{H} 13$ steel into austenite. For various alloy tool steels, the temperatures of the surface layer during heat treatment should be higher than the austenized temperature, and the duration should be kept long, such that, as we mentioned for H13 steel, the temperatures of the surface layer during heat treatment should be higher than the equilibrium eutectoid temperature of H13's austenized temperature at $1010{ }^{\circ} \mathrm{C}$. Following this logic, the temperature of the surface layer should be high enough for quenching to take place so that it will enable the complete transformation of austensite into martensite.

Fig. 4 presents a temperature distribution for the laser surface hardening of H13 steel under different laser energy densities. This figure demonstrates that the critical phase transition temperature of $\mathrm{H} 13$ decreased upon increasing the laser energy densities; the critical phase transition temperature of $\mathrm{H} 13$ in the as-received condition is higher than the temperature in the quenched condition under the same energy density. This situation exists because the H13 steel in the as-received condition presents a spheroidal structure that consists of particles of $\mathrm{M}_{23} \mathrm{C}_{6}$ and $\mathrm{M}_{7} \mathrm{C}_{3}$ carbides $(\mathrm{M}=\mathrm{Cr}$, $\mathrm{Fe}$ ), dispersed in a matrix and, therefore, the temperatures should be high enough, and the duration long enough, for the particles these carbides to dissolve into martensite when the transformation hardening occurs.

Because the H13 steel is an air hardening steel, the most important factor in the laser transformation hardening of $\mathrm{H} 13$ steel depends on whether the peak temperature exceeds the critical phase transition temperature; the longer duration that allows the metallic carbide particles to dissolve into the matrix and the cooling rate after heating have less effect when causing the transformation hardening. When the increased laser energy densities caused higher temperature or longer durations for laser heating of $\mathrm{H} 13$ steel, the critical phase transition temperature of $\mathrm{H} 13$ is closer to its equilibrium eutectoid temperature of austenized temperature at $1010{ }^{\circ} \mathrm{C}$.

\section{Conclusions}

There were several significantly different characteristics in the microstructures that evolved in the laser-affected layers of the laser hardened H13 steel. We noted that the basic microstructure in the melt layer was dendrites surrounded by an extremely fine lamellar structure. The hardened layer was characterized by martensite within the metallic carbides precipitated at the grain boundary. In the heat-affected layer, the metallic carbide particles became larger and many more

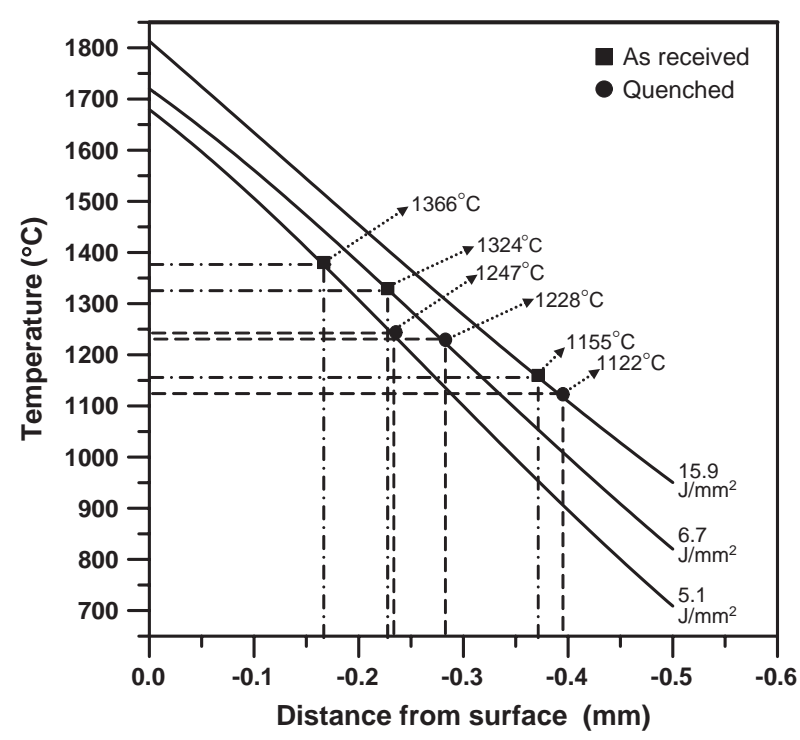

Fig. 4. Temperature distribution of the surface layer obtained for the laser surface hardening of $\mathrm{H} 13$ steel in its quenched and as-received conditions under different laser energy densities. 
were formed as a result of tempering. We applied the modified Ashby-Eastering heat-transfer equation to the laser surface transformation hardening of H13 steel by taking into account several effects that can be very significant in causing surface melting and a higher critical phase transformation temperature of the laser hardening cycles. For laser surface hardening of the H13 steel under different laser energy densities in the melt, we noted that the critical phase transition temperature of the hardened area of H13 steel decreased upon increasing the laser energy densities and that the critical phase transition temperature of $\mathrm{H} 13$ in the as-received condition was higher than the corresponding temperature in the quenched condition under the same energy density. The larger the grain size or the more heterogeneous the structure, the higher the temperature and the longer the duration required to transform the $\mathrm{H} 13$ steel into austenite.

\section{References}

[1] L.X. Yang, X.F. Peng, B.X. Wang, Heat and Mass Transfer 44 (2001) $4455-4473$

[2] W.M. Steen, Journal of Applied Physics 51 (1980) 946.

[3] W.M. Steen, Laser Material Processing, Springer, London, 1991, pp. $156-170$

[4] R.A. Ganeev, Journal of Materials Processing Technology 121 (2002) 414-419.

[5] C. Olaineck, Heat Treatment of Metals 1 (1996) 17-19.

[6] R. Komanduri, Z.B. Hou, Heat and Mass Transfer 44 (2001) $2845-2862$

[7] S. Kou, D.K. Sun, Y.P. Lee, Met A 14 (1983) 643-653.

[8] J. Goldak, A. Chakravarti, M. Bibby, Met B 15 (1984) 299-305.

[9] M.F. Ashby, Laser Processing of Materials, AIME, New York, 1985, pp. $225-234$.

[10] M.A. Ashby, E. Easterling, Acta Metallurgica 32 (1984) 1935-1962.

[11] H.R. Shercliff, M.A. Ashby, Met A 22 (1991) 438-446. 